\title{
Spatial-temporal analysis of temperature in Lake Shira based on long-term observations
}

\author{
Olga S. Volodko ${ }^{1}$, Lidiya A. Kompaniets ${ }^{1}$ and Lyudmila V. Gavrilova ${ }^{2}$ \\ ${ }^{1}$ Institute of Computational Modeling SB RAS, Krasnoyarsk, Russia \\ ${ }^{2}$ Siberian Federal University, Krasnoyarsk, Russia
}

\begin{abstract}
Long-term in-situ measurements of temperature were conducted in lake Shira during 2013-2015. The principal component analysis of temperature time series allowed to identify period of generation and propagation of internal waves. The spectral analysis revealed the dominance of the oscillations with periods of $21.3,10.6$ and $5.3 \mathrm{~h}$.
\end{abstract}

\section{Keywords}

In-situ measurements, internal waves, spectral analysis, isotherms.

\section{Introduction}

The dynamics of water currents are studied intensively in order to analyze the distribution of impurities and phytoplankton and, thus, to determine characteristics of water systems.

Lake Shira located in the Republic of Khakassia, Eastern Siberia, is an enclosed saline lake with only a small tributary of the Son River. In the period of summer stratification, the wind stress is a main factor induced the water currents.

The observations on many stratified lakes confirm that one of the most common wind reactions is the occurrence of internal waves [1], which determine the intensity of mixing in the coastal zone, and therefore biological processes and water quality in lake.

In present work, the periods of internal waves has been determined using spectral estimates of temperature of 2013-2015.

\section{Long-term temperature measurements}

In summer of 2013-2015 in lake Shira long-term temperature measurements were carried out at several stations of the lake, as shown in Figure 1. The temperature measurements were performed using thermal circuits. The temperature were measured with interval of 1-1.5 m and with accuracy of $0.5^{\circ} \mathrm{C}$ in $2013-2014$, and the accuracy of $0.1^{\circ} \mathrm{C}$ in 2015 .

The temperature data of 2013-2014 of four stations T2, T3, T4, T5 were analyzed from 03.07.2013 to 05.08 .2013 and from 01.07 .2014 to 21.07 .2014 . The data of 2015 were analyzed from

SDM-2021: All-Russian conference, August 24-27, 2021, Novosibirsk, Russia @osv@icm.krasn.ru (O.S. Volodko); lv.gavrilova@gmail.com (L.V. Gavrilova)

(c) (1) ๑ 2021 Copyright for this paper by its authors. Use permitted under Creative Commons License Attribution 4.0 International (CC BY 4.0).

CEUR Workshop Proceedings (CEUR-WS.org) 

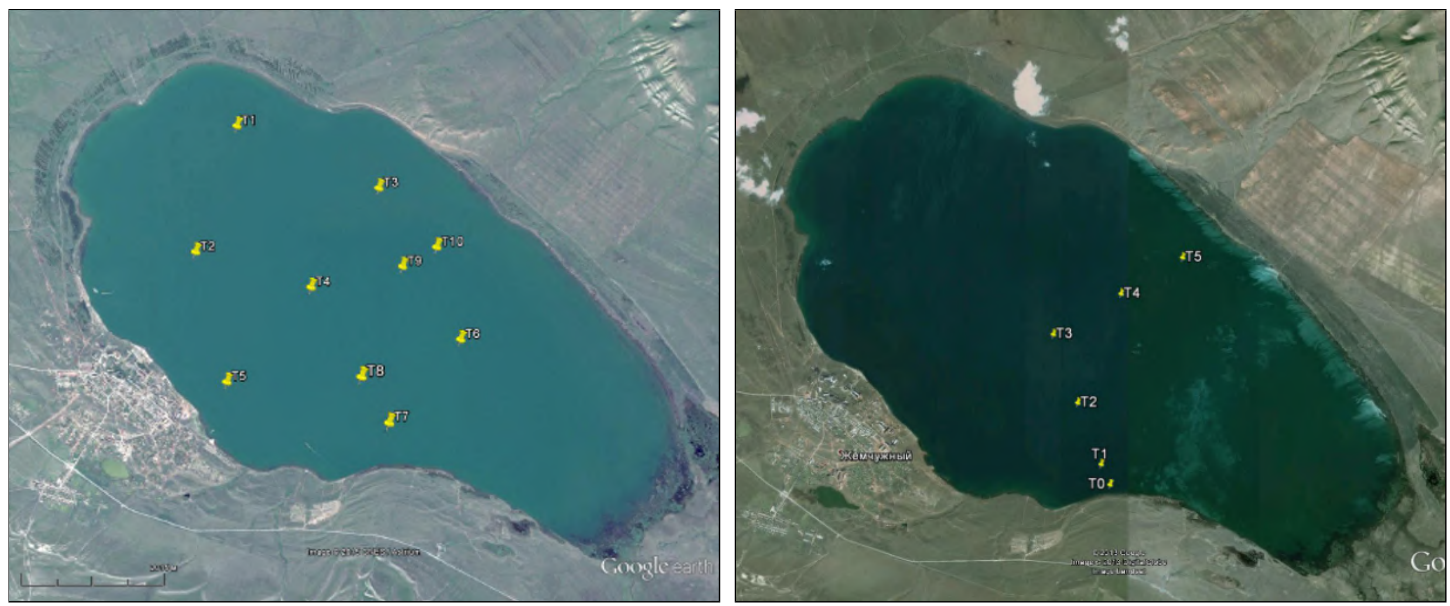

Figure 1: The stations of temperature measurements in 2013 (left), in 2014-2015 (right).

seven stations T1, T2, T4, T7, T8, T9, T10 with depth 15.7, 23.6, 24.4, 13.8, 17.5, 17 and $12.9 \mathrm{~m}$ correspondingly of two periods from 8.07.2015 to 11.07.2015 and from 01.07.2015 to 01.08.2015.

\section{Spectral analysis}

The spectral estimates of temperature were found using the method of averaged periodogram with Blackman - Harris window and the Welch's method [2]. In the last method signal is split up into eight overlapping segments and then averaged windowed using Blackman - Harris window. On the each segment the periodorgam is calculated by computing discrete Fourier transform

$$
D_{n}=\frac{1}{N} \sum_{m=0}^{N-1} f_{m} W^{m n}, \quad n=0,1,2, \ldots, N-1,
$$

where $\left\{f_{m}, m=0,1,2, \ldots, N-1\right\}, W=e^{-2 \pi i / N}$ is discrete exponential functions. The discrete Fourier transformation is computes using fast Fourier transformation, that allows to obtain result in time of $O(N \log N)$.

In article [3] were presented analysis of temperature data in period from 01.07.2015 to 01.08.2015 using method of empirical orthogonal functions (principal component analyses). The analysis identified periods of generation and propagation of internal waves. During the time-period from 08.07.2015 to 11.07.2015 the internal waves were observed with period 7 and 9 hours (Figure 2). Therefore, these 4 days and the entire measurement time period from 01.07.2015 to 01.08.2015 were chosen for spectral analysis.

The spectral estimations in period from 08.07.2015 to 11.07.2015 were found for original data, in period from 01.07.2015 to 01.08.2015 the temperature data were pre-processed with decimation every 15 minutes (Table 1 ). The Figures $3-8$ shows temperature spectrums.

The spectral analysis of temperature showed the frequencies longwave oscillations for period four days are include in frequencies longwave oscillations for period a month (see Table 1). 


\section{Table 1}

The spectral estimations of temperature of 2015.

\begin{tabular}{|c|c|c|c|c|c|}
\hline $\begin{array}{l}\text { Frequency, } \\
1 / \mathrm{hr}\end{array}$ & $\begin{array}{l}\text { Period, } \\
\mathrm{h}\end{array}$ & $\begin{array}{l}\text { Spectral power } \\
\text { density, } W /(1 / h)\end{array}$ & $\begin{array}{l}\text { Frequency, } \\
1 / \mathrm{h}\end{array}$ & $\begin{array}{l}\text { Period, } \\
\mathrm{h}\end{array}$ & $\begin{array}{l}\text { Spectral power } \\
\text { density, } W /(1 / h)\end{array}$ \\
\hline \multicolumn{3}{|c|}{ Station T1 } & \multicolumn{3}{|c|}{ Station T2 } \\
\hline \multicolumn{6}{|c|}{ 08.07.2015-11.07.2015 } \\
\hline 0.04688 & 21.3 & 4.415 & 0.07031 & 14.2 & 0.00728 \\
\hline 0.1172 & 8.5 & 0.2474 & 0.1172 & 8.5 & 0.004908 \\
\hline 0.1875 & 5.3 & 0.08537 & 0.1875 & 5.3 & 0.002681 \\
\hline \multicolumn{6}{|c|}{ 01.07.2015-01.08.2015 } \\
\hline 0.04688 & 21.3 & 0.9873 & 0.03125 & 32 & 0.2594 \\
\hline 0.0625 & 16 & 0.9592 & 0.0625 & 16 & 0.2738 \\
\hline 0.09375 & 10.6 & 3.091 & 0.09375 & 10.6 & 0.2059 \\
\hline 0.1172 & 8.5 & 2.891 & 0.125 & 8 & 0.1107 \\
\hline 0.1953 & 5.1 & 1.396 & 0.1484 & 6.7 & 0.1829 \\
\hline & & & 0.1953 & 5.1 & 0.07305 \\
\hline \multicolumn{3}{|c|}{ Station T4 } & \multicolumn{3}{|c|}{ Station T7 } \\
\hline \multicolumn{6}{|c|}{ 08.07.2015-11.07.2015 } \\
\hline 0.04688 & 21.3 & 0.04632 & 0.04688 & 21.3 & 0.04848 \\
\hline 0.09375 & 10.6 & 0.002482 & 0.1172 & 8.5 & 0.003557 \\
\hline 0.1875 & 5.3 & 0.0003167 & 0.1875 & 5.3 & 0.001335 \\
\hline \multicolumn{6}{|c|}{$01.07 .2015-01.08 .2015$} \\
\hline 0.04688 & 21.3 & 0.1065 & 0.03125 & 21.3 & 6.179 \\
\hline 0.0625 & 16 & 0.4059 & 0.08594 & 11.6 & 3.486 \\
\hline 0.08594 & 11.6 & 0.2201 & 0.1094 & 9.1 & 0.5561 \\
\hline 0.1016 & 9.8 & 0.2497 & 0.1328 & 7.5 & 0.1603 \\
\hline 0.1484 & 6.7 & 0.1335 & 0.1484 & 6.7 & 0.2788 \\
\hline 0.1797 & 5.5 & 0.04446 & 0.1797 & 5.5 & 0.1763 \\
\hline \multicolumn{3}{|c|}{ Station T8 } & \multicolumn{3}{|c|}{ Station T9 } \\
\hline \multicolumn{6}{|c|}{$08.07 .2015-11.07 .2015$} \\
\hline 0.09375 & 10.6 & 0.0007315 & 0.07031 & 14.2 & 0.001293 \\
\hline 0.1406 & 7.1 & 0.001111 & 0.1406 & 7.1 & 0.001111 \\
\hline & & & 0.2109 & 4.7 & 0.001112 \\
\hline \multicolumn{6}{|c|}{$01.07 .2015-01.08 .2015$} \\
\hline 0.07031 & 14.2 & 0.3639 & 0.02344 & 42.6 & 1.399 \\
\hline 0.08594 & 11.6 & 0.814 & 0.03906 & 25.6 & 0.522 \\
\hline 0.125 & 8 & 0.1068 & 0.0625 & 14.2 & 0.6069 \\
\hline 0.1406 & 7.1 & 0.1728 & 0.08594 & 11.6 & 0.8786 \\
\hline 0.1563 & 6.3 & 0.1129 & 0.1563 & 6.3 & 0.08016 \\
\hline 0.1953 & 5.1 & 0.06089 & 0.2031 & 4.9 & 0.1576 \\
\hline
\end{tabular}




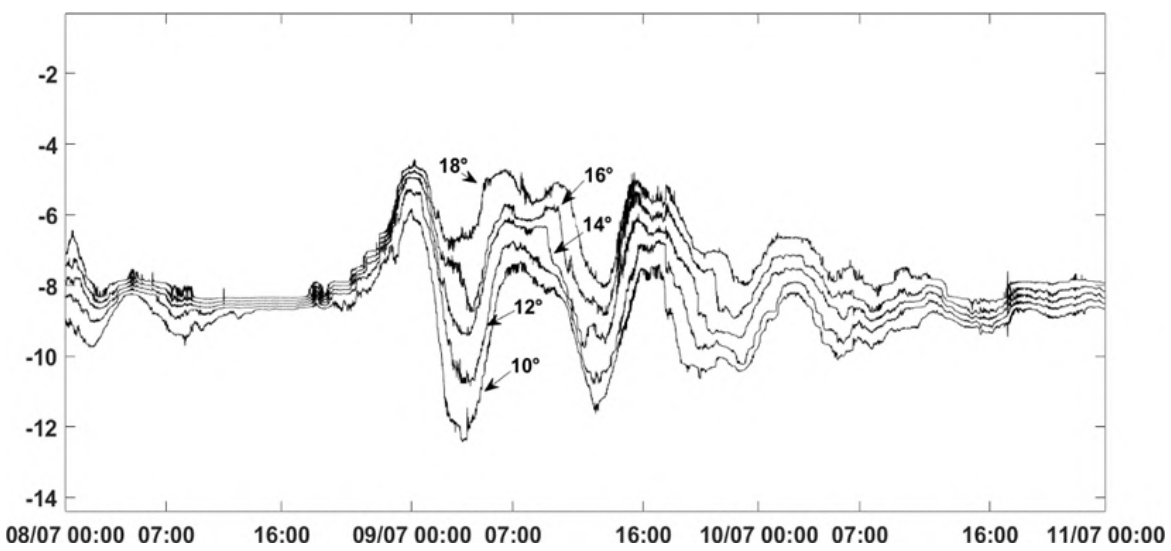

Figure 2: The isotherms in the station $\mathrm{T} 1$ of period from 08.07 .15 to $11.07 .2015, T=10,12,14,16,18^{\circ} \mathrm{C}$.
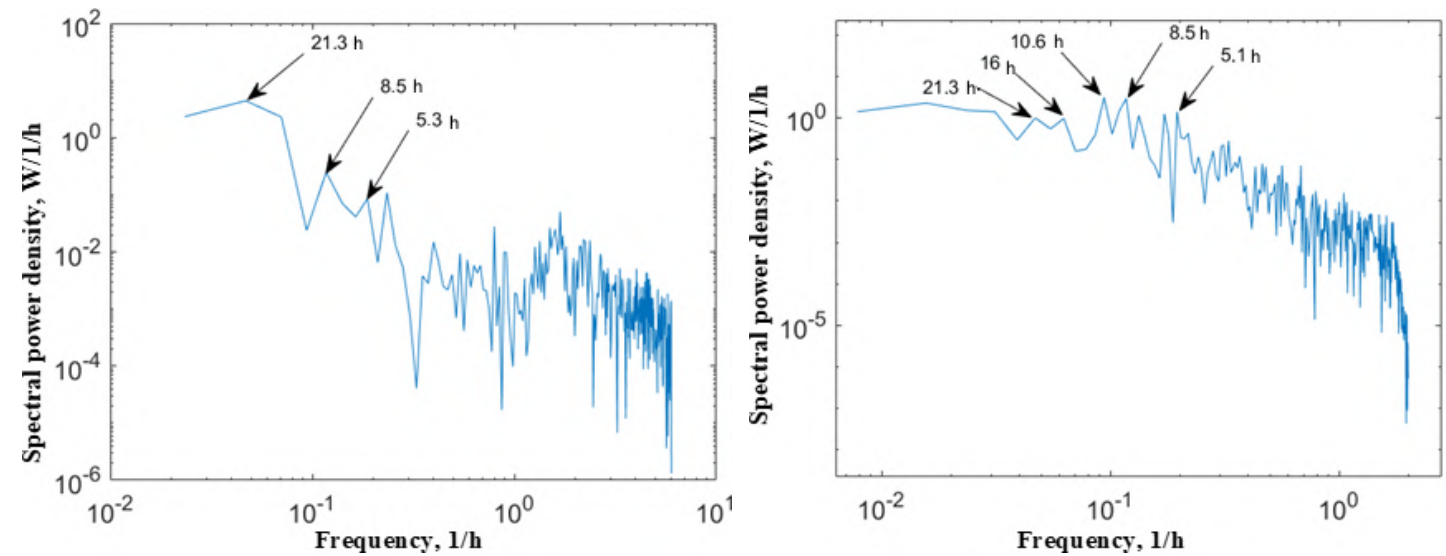

Figure 3: The spectral density of temperature in the station T1 in periods 08.07.2015-11.07.2015 (left) and 01.07.2015-01.08.2015 (right).
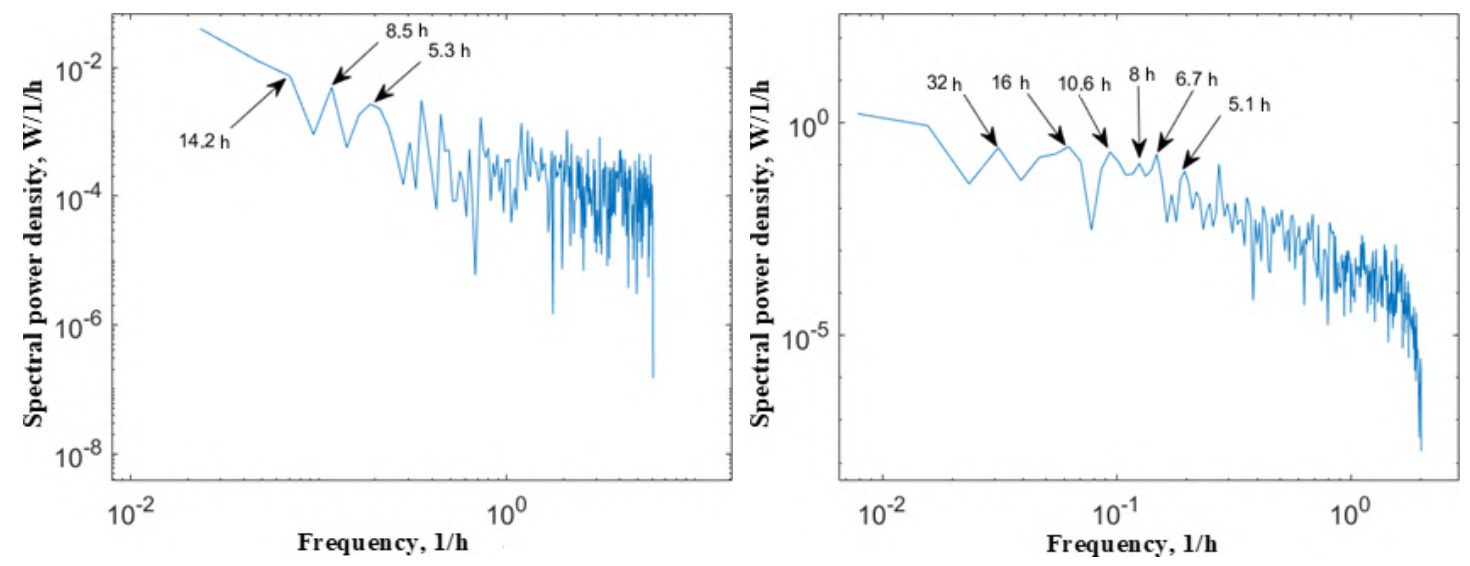

Figure 4: The spectral density of temperature in the station T2 in periods 08.07.2015-11.07.2015 (left) and 01.07.2015-01.08.2015 (right). 

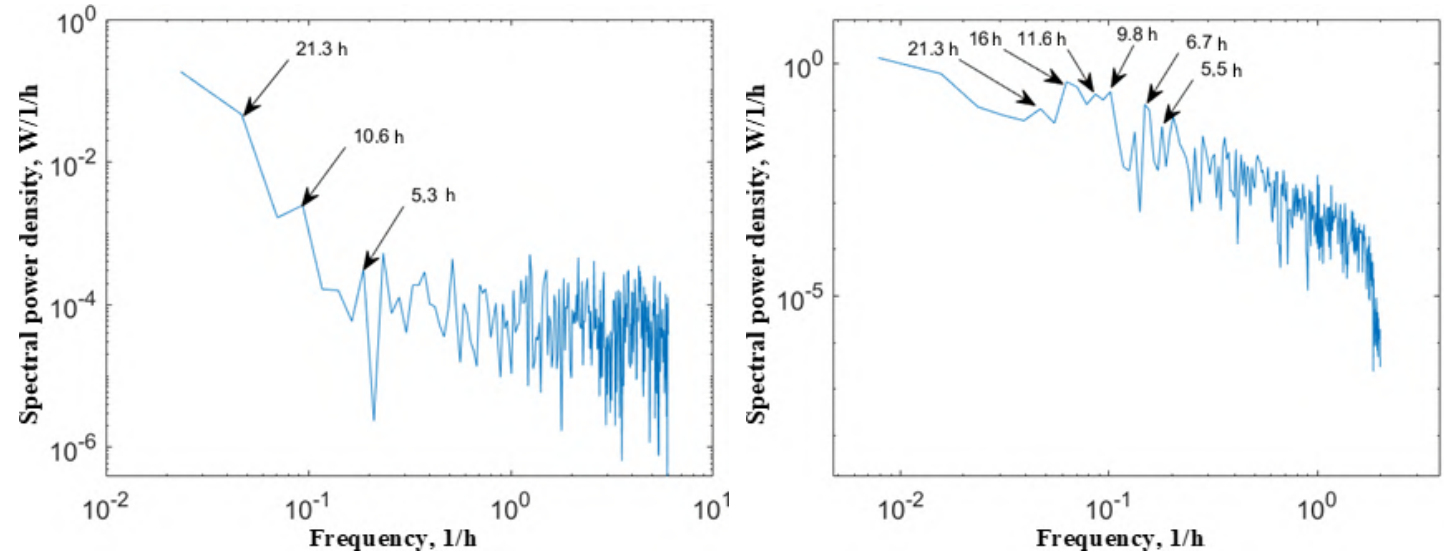

Figure 5: The spectral density of temperature in the station T4 in periods 08.07.2015-11.07.2015 (left) and 01.07.2015-01.08.2015 (right).
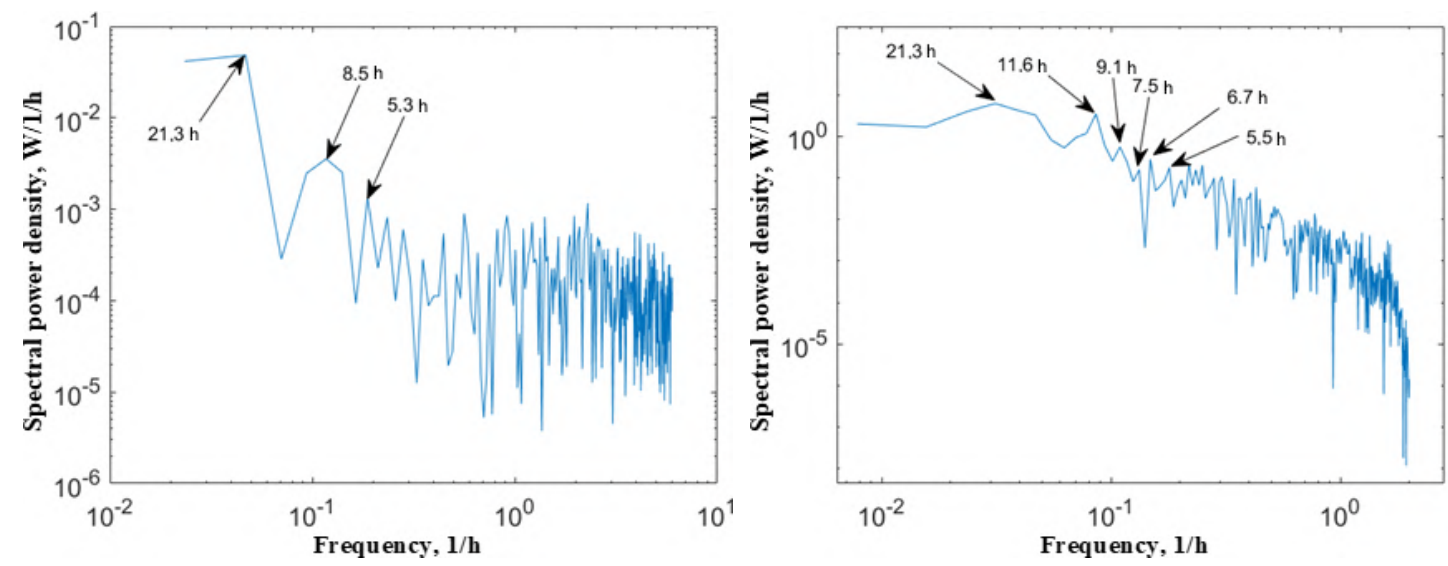

Figure 6: The spectral density of temperature in the station T7 in periods 08.07.2015-11.07.2015 (left) and 01.07.2015-01.08.2015 (right).
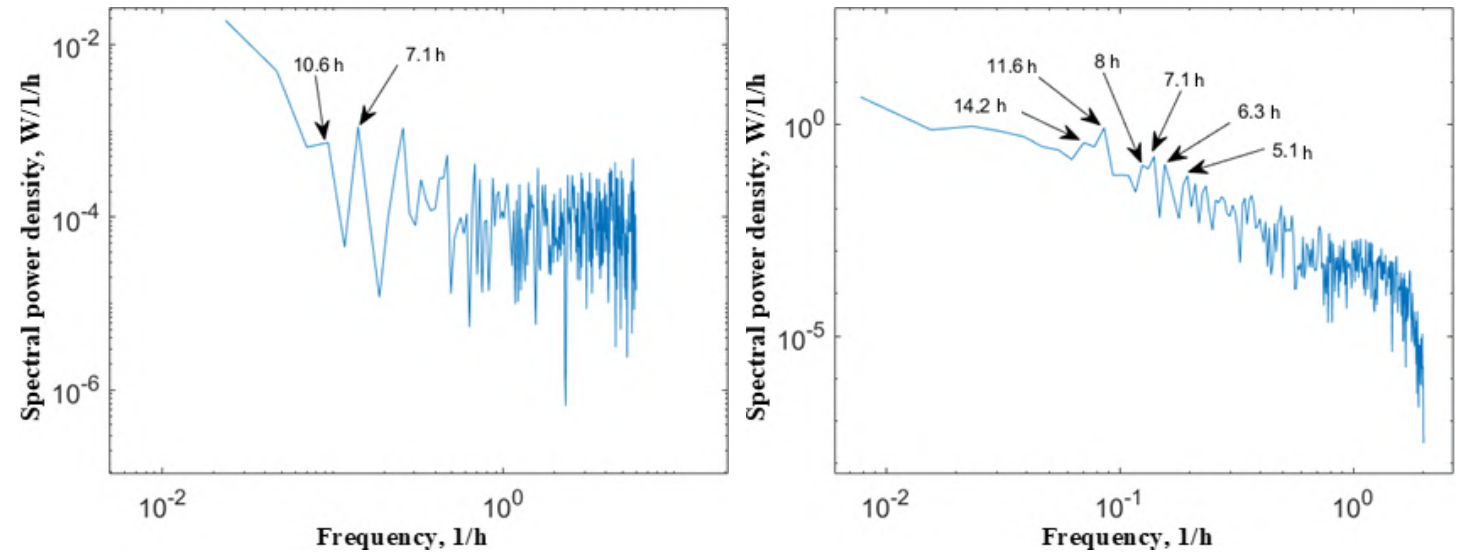

Figure 7: The spectral density of temperature in the station T8 in periods 08.07.2015-11.07.2015 (left) and 01.07.2015-01.08.2015 (right). 

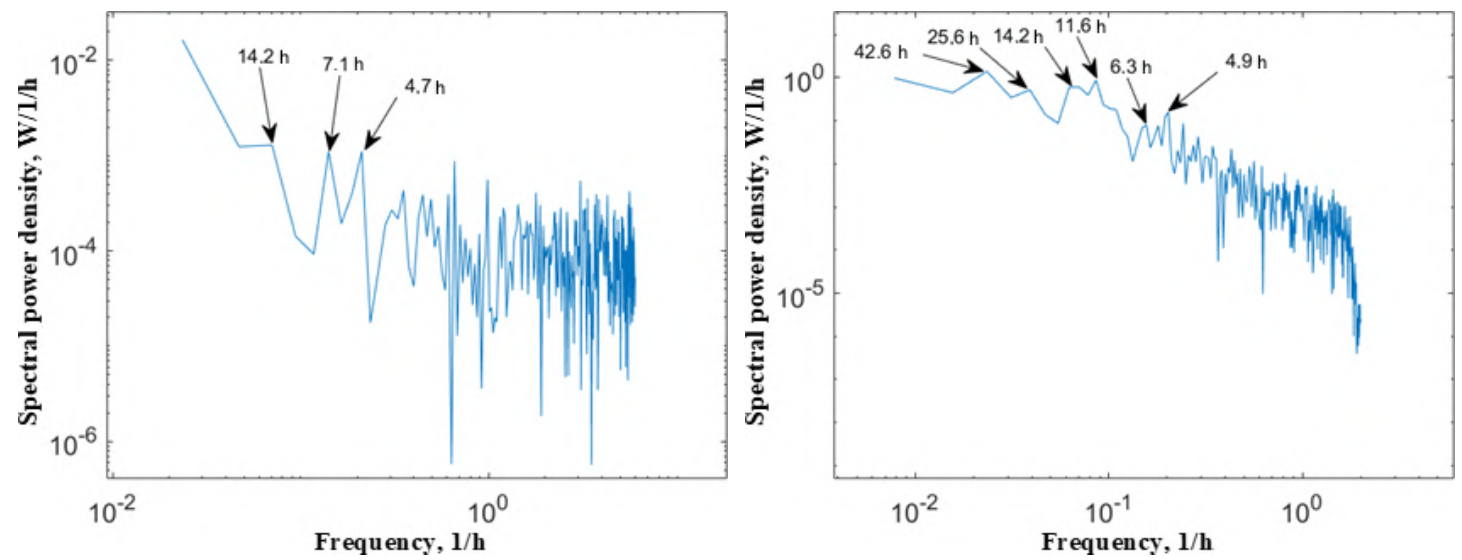

Figure 8: The spectral density of temperature in the station T9 in periods 08.07.2015-11.07.2015 (left) and 01.07.2015-01.08.2015 (right).

The spectral estimations of temperature of 2013-2014 are presented in Tables 2 and 3.

In summer 2013, 2014 and 2015, the spectral analysis of the temperature data showed the presence of maxima at a frequencies corresponding to long-time periods of 32, 26.5, 21.3, $14.2 \mathrm{~h}$. In 2015 in station T10 were identified maximum corresponding to period of $42.6 \mathrm{~h}$, that multiple $21.3 \mathrm{~h}$. It should be emphasized the presence at the same time of maxima at frequencies corresponding to long periods, and periods $2-4$ times smaller: $42.6 \mathrm{~h}-21.3 \mathrm{~h}, 32 \mathrm{~h}-16 \mathrm{~h}$, $26.5 \mathrm{~h}-13.3 \mathrm{~h}, 14.2 \mathrm{~h}-21.3 \mathrm{~h}$.

\section{Table 2}

The spectral estimations of temperature of 2014.

\begin{tabular}{|c|c|c|c|c|c|}
\hline $\begin{array}{l}\text { Frequency, } \\
1 / \mathrm{h}\end{array}$ & $\begin{array}{l}\text { Period, } \\
\mathrm{h}\end{array}$ & $\begin{array}{c}\text { Spectral power } \\
\text { density, } W /(1 / h)\end{array}$ & $\begin{array}{l}\text { Frequency, } \\
1 / \mathrm{h}\end{array}$ & $\begin{array}{c}\text { Period, } \\
\mathrm{h}\end{array}$ & $\begin{array}{c}\text { Spectral power } \\
\text { density, } W /(1 / h)\end{array}$ \\
\hline \multicolumn{3}{|c|}{ 01.07.2015-21.07.2015 } & \multicolumn{3}{|c|}{ 19.07.2014-30.07.2014 } \\
\hline \multicolumn{3}{|c|}{ Station T3 } & \multicolumn{3}{|c|}{ Station T4 } \\
\hline 0.03906 & 25.6 & 0.4086 & 0.03125 & 32 & 0.5518 \\
\hline 0.04688 & 21.3 & 0.2974 & 0.04688 & 21.3 & 0.3595 \\
\hline 0.07031 & 14.2 & 0.1158 & 0.0625 & 16 & 0.9857 \\
\hline 0.09375 & 10.6 & 0.9203 & 0.07813 & 12.8 & 0.6905 \\
\hline 0.1172 & 8.5 & 2.522 & 0.1094 & 9.1 & 2.228 \\
\hline 0.1382 & 7.2 & 0.2607 & 0.1563 & 6.4 & 1.394 \\
\hline 0.1797 & 5.6 & 0.2284 & & & \\
\hline \multicolumn{6}{|c|}{ Station T5 } \\
\hline 0.03906 & 25.6 & 12.52 & & & \\
\hline 0.0625 & 16 & 4.52 & & & \\
\hline 0.0859 & 11.6 & 6.148 & & & \\
\hline 0.1016 & 9.8 & 10.81 & & & \\
\hline 0.1406 & 7.1 & 4.645 & & & \\
\hline 0.1875 & 5.3 & 16.91 & & & \\
\hline
\end{tabular}


Table 3

The spectral estimations of temperature of 2013.

\begin{tabular}{|c|c|c|c|c|c|}
\hline $\begin{array}{l}\text { Frequency, } \\
\qquad 1 / \mathrm{h}\end{array}$ & $\begin{array}{l}\text { Period, } \\
\mathrm{h}\end{array}$ & $\begin{array}{l}\text { Spectral power } \\
\text { density, } W /(1 / h)\end{array}$ & $\begin{array}{l}\text { Frequency, } \\
1 / \mathrm{h}\end{array}$ & $\begin{array}{l}\text { Period, } \\
\mathrm{h}\end{array}$ & $\begin{array}{l}\text { Spectral power } \\
\text { density, } W /(1 / h)\end{array}$ \\
\hline \multicolumn{6}{|c|}{ 03.07.2013-05.08.2013 } \\
\hline \multicolumn{3}{|c|}{ Station T2 } & \multicolumn{3}{|c|}{ Station T3 } \\
\hline 0.0375 & 26.6 & 60.74 & 0.0375 & 26.6 & 44.62 \\
\hline 0.04688 & 21.3 & 22.77 & 0.06094 & 16.4 & 11.2 \\
\hline 0.075 & 13.3 & 14.82 & 0.07031 & 14.2 & 18.49 \\
\hline 0.08437 & 11.8 & 31.83 & 0.08437 & 11.8 & 26.12 \\
\hline 0.1125 & 8.8 & 23.79 & 0.1125 & 8.8 & 17.67 \\
\hline 0.1453 & 6.9 & 11.2 & 0.1453 & 6.9 & 2.913 \\
\hline 0.1875 & 5.3 & 2.842 & 0.1828 & 5.4 & 2.894 \\
\hline \multicolumn{3}{|c|}{ Station T4 } & \multicolumn{3}{|c|}{ Station T5 } \\
\hline 0.0375 & 26.6 & 19.2 & 0.0375 & 26.6 & 25.89 \\
\hline 0.06094 & 16.4 & 15.81 & 0.05156 & 19.4 & 3.271 \\
\hline 0.075 & 13.3 & 24.26 & 0.075 & 13.3 & 7.235 \\
\hline 0.08906 & 11.2 & 29.34 & 0.08437 & 11.8 & 20.77 \\
\hline 0.09844 & 10.1 & 17 & 0.1078 & 9.2 & 24.13 \\
\hline 0.1125 & 8.8 & 14.01 & 0.1266 & 7.9 & 16.67 \\
\hline 0.1453 & 6.9 & 4.523 & 0.1453 & 6.9 & 4.009 \\
\hline 0.1828 & 5.4 & 4.711 & 0.1828 & 5.4 & 5.497 \\
\hline
\end{tabular}
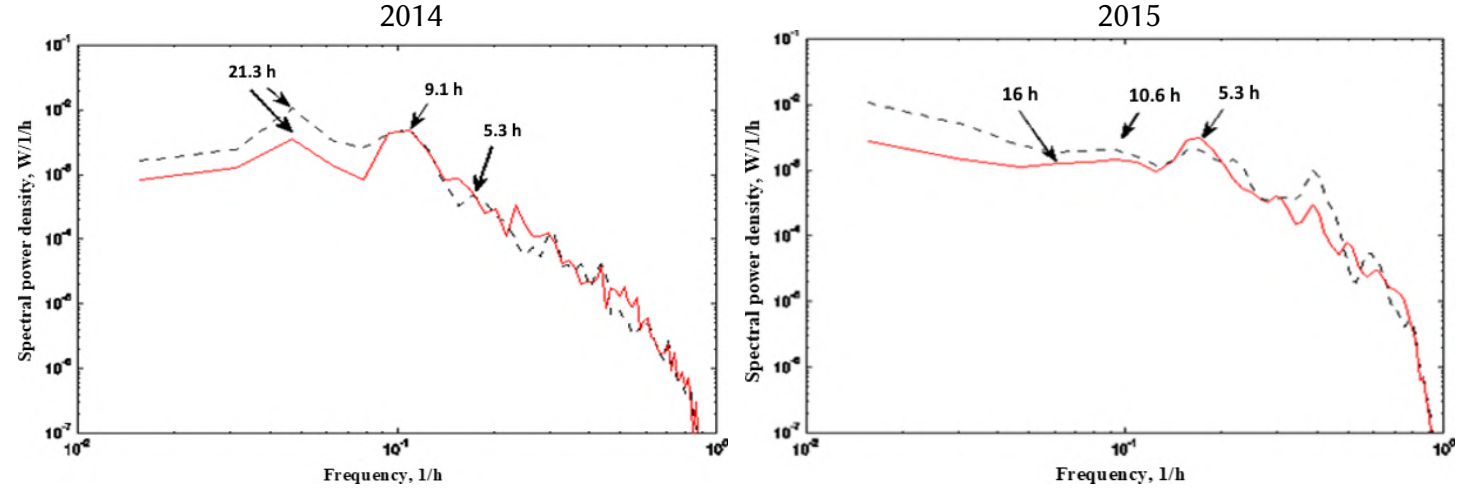

Figure 9: The spectral power of current velocity in the summer of 2014 and 2015.

The spectral estimates of temperature are consistent with the spectral estimates of the current velocity in lake Shira (Figure 9). These spectral estimates were presented in work [4]. 


\section{Conclusions}

The spectral analysis of the temperature data of summer 2013, 2014 and 2015 were allowed determining a period of internal waves in lake Shira. The spectral estimates of temperature are consistent with the spectral estimates of the current velocity. Based on spectral analysis over a period of three years, we can expect the presence of internal waves of such periods in lake Shira in other years.

\section{Acknowledgments}

This work is supported by the Krasnoyarsk Mathematical Center and financed by the Ministry of Science and Higher Education of the Russian Federation in the framework of the establishment and development of regional Centers for Mathematics Research and Education (agreement No. 075-02-2021-1384).

The authors thanks to Tatyana Schidlovskaya for the computation the spectral estimates of temperature of 2015.

\section{References}

[1] Mortimer C.H. A review of temperature measurement in limnology // Internationale Vereinigung für Theoretische und Angewandte. Limnologie: Mitteilungen, 1953. Vol. 1(1). P. 1-25.

[2] Welch P. The use of fast Fourier transform for the estimation of power spectra: a method based on time averaging over short, modified periodograms // IEEE Transactions on Audio and Electroacoustics. 1967. Vol. 15(2). P. 70-73.

[3] Volodko O.S., Kompaniets L.A., Gavrilova L.V. Principal component analysis in the problem of analysis hydrophysical characteristics in open water bodies // Neuroinformatics, Its Applications and Data Analysis. Krasnoyarsk, 2018. P. 23-29.

[4] Volodko O.S., Ishanov S.A., Kashhenko N.M. The spectral analysis of dynamic of currents in lake Shira // Proceedings of International Conference "Applied Mathematics, Computational Science and Mechanics: Current Problems”. Voronezh, 2016. P. 218-220. 